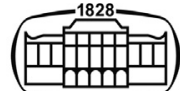

AKADÉMIAI KIADÓ

IMAGING

\title{
Congenital coronary artery fistula to the right atrium assessed with Cardiac CT
}

\section{ERICA MAFFEI ${ }^{1}$, FRANCESCO DI PEDE ${ }^{2}$, ELISABETTA BARBIERI ${ }^{1}$ and FILIPPO CADEMARTIRI ${ }^{3 *}$ @}

\author{
${ }^{1}$ Department of Radiology, Area Vasta 1, ASUR Marche, Urbino, Italy \\ ${ }^{2}$ Department of Cardiology, San Donà Hospital, San Donà di Piave, Venice, Italy \\ ${ }^{3}$ SDN IRCCS, Naples, Italy
}

Received: May 28, 2020 • Accepted: June 09, 2020

\section{CASE REPORT}

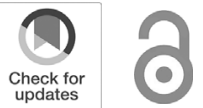

IMAGING 12 (2020) 1, 11-12

DOI: $10.1556 / 1647.2020 .00004$

(c) 2020 The Author(s)

*Corresponding author. Department of Radiology, Area Vasta 1, ASUR Marche, Ospedale Civile "Santa Maria della Misericordia" di Urbino, viale Federico Comandino, 70, 61029, Urbino, Italy, Tel.:+39 0722301222 ; fax: +390722201858

E-mail: filippocademartiri@gmail.com

\section{ABSTRACT}

A 50-year-old female with palpitations, dyspnoea and slightly dilated left ventricle at echocardiography was referred to Cardiac CT (CCT) for coronary artery assessment. CCT revealed a large fistula from the left main coronary artery to the right atrium, associated with agenesia of the inferior vena cava.

\section{KEYWORDS}

congenital coronary fistula, right atrium, coronary arteries, computed tomography coronary angiography

A 50-year-old female (D.G.) suffering from palpitations and dyspnoea was referred to Cardiac CT (CCT) (Fig. 1; Movie 1). Prior to that echocardiography reported a slightly dilated left ventricle with preserved systolic function. CCT showed normal three vessel coronary anatomy without significant stenosis. The left coronary artery was significantly enlarged $(11 \mathrm{~mm})$ and gave birth in the distal caudal part to a very large $(10 \mathrm{~mm})$ fistula to cranial portion of the right atrium (Fig. $1-\mathrm{A}-\mathrm{D}$ arrowheads). The course of the fistula was retro-aortic. CCT also showed the presence of a valve in the distal part of the fistula at the level of inlet into the right atrium (Fig. $1-\mathrm{D}$ arrow). The left ventricular ejection fraction and systolic function at rest was normal (55\%) with a dilated left ventricular end-diastolic volume $\left(120 \mathrm{~mL} / \mathrm{m}^{2}\right)$; the right ventricle showed a low normal ejection fraction (48\%) with a dilated end-diastolic volume $\left(128 \mathrm{~mL} / \mathrm{m}^{2}\right)$; the right atrium was not significantly enlarged.

The patient underwent conventional coronary angiography (Fig. 1; Movie 2) that confirmed the fistula (Fig. 1 - E-G; arrowheads).

As a collateral finding CCT detected a dilated azygos vein $(22 \mathrm{~mm})$ draining in a dilated hemi-azygos vein (18 mm) (Fig. 1 - H-L; arrowheads); the hemiazygos vein continued below the diaphragm and drained into the left renal artery. Inferior vena cava was not visualized and sovra-hepatic veins drained directly into the right atrium. These findings are consistent with congenital agenesia of the inferior vena cava. The patient was treated medically.

CCT is a reliable diagnostic method for the anatomical definition a classification of coronary artery fistulas and associated abnormalities $[1,2]$. 


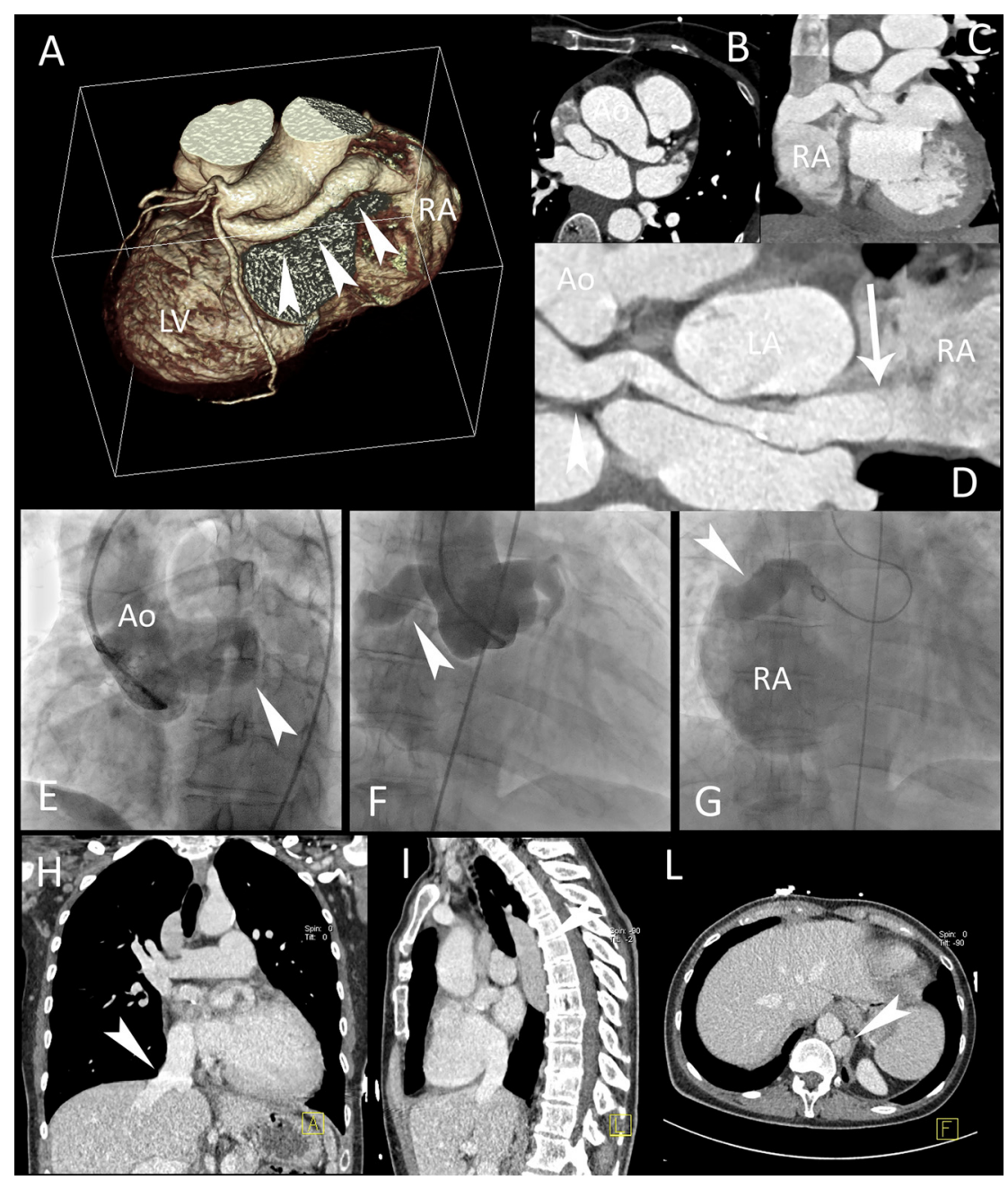

Figure 1. Cardiac CT and Conventional Coronary Angiography findings. Cardiac CT (A-D) showed a large congenital conduit (i.e. fistula) between the caudal distal portion of the left main coronary artery and the right atrium (A; arrowheads). The left main was enlarged (B) and the fistula actually terminated at the passage between the superior vena cava and the right atrium (C); at that level CCT showed a very thin valvular structure (D; arrow). Conventional coronary angiography (E-G; arrowheads) confirmed the findings. From CCT it was also possible to diagnose an anomaly of venous return to the heart $(\mathrm{H}-\mathrm{L})$ with absent intra-hepatic inferior vena cava and a vicariating azygos/hemiazygos system. Abbreviations: Ao $=$ Ascending Aorta; RA $=$ Right Atrium; LA $=$ Left Atrium; LV $=$ Left Ventricle

Funding sources: None.

Authors' contribution: All authors have read and accepted the final version of the manuscript.

Conflict of interests: None.

\section{REFERENCES}

[1] Mastroroberto P, Olivito S: Giant congenital fistula of the circumflex coronary artery with drainage into right atrium. Heart Lung Circ 2012 Dec; 21(12): 809-10.
[2] Yoon AJ, Siddiqi S, Lituchy AE, Cao JJ: Images in cardiovascular medicine. Giant left circumflex coronary fistula to the right atrium. Circulation 2010 Aug 24; 122(8): e434-5.

\section{Supplementary Material}

Supplementary material can be found at: https://doi.org/10. 1556/1647.2020.00004.

Movie 1. 3D Cardiac CT (CCT) showing the fistula between the left main and the inlet of superior vena cava into the right atrium.

Movie 2. Conventional coronary angiogram of the fistula.

Open Access statement. This is an open-access article distributed under the terms of the Creative Commons Attribution-NonCommercial 4.0 International License (https:// creativecommons.org/licenses/by-nc/4.0/), which permits unrestricted use, distribution, and reproduction in any medium for non-commercial purposes, provided the original author and source are credited, a link to the CC License is provided, and changes - if any - are indicated. 